\title{
A 360 Degree Approach to Resolving Uncertainty and Prioritising Delivery of Coastal Adaptation, Resilience and Environmental Protection for the Future Economic Growth of Jersey, Channel Isles
}

\author{
Tara-Leigh McVey, AECOM, Basingstoke, England \\ Jason Drummond, AECOM, Bristol, England \\ Jamie Mason, Government of Jersey, St Helier, Jersey \\ Fiona Glover, Government of Jersey, St Helier, Jersey \\ Jenny Brown, National Oceanography Centre, Liverpool, England
}

\begin{abstract}
The island of Jersey has a rich history influenced by natural and man-made change; particularly the fortifications constructed as defensive structures during periods of conflict, from the Napoleonic period through to 1940's. Over the next century Jersey faces a growing challenge from the predicted impacts of climate change via rising sea levels combined with increasingly intense rainfall which will result in an increase to the extents of coastal and pluvial flooding. Jersey needs to be prepared and resilient; to support a digital Island that attracts international business, providing a secure and safe location. Jersey's shoreline policies balance the Island's environmental legislation and economic policies, but a priority for the Government is flood avoidance, mitigation and development opportunities through planning policy and asset adaptation in a way that supports the Island's prosperity. This includes consideration of advancing the 'defence' line. A 360 degree approach is taken to deliver an island wide coastal resilience plan, which includes pluvial flooding as well as coastal flooding - the outcome will be the Jersey Shoreline Management Plan (SMP). This paper presents the first ever emerging coastal flood and erosion mapping for the whole island under the jurisdiction of the Government of Jersey. The mapping is supported by shoreline planning and policy over the next 20,50 and 100 years, which augments the plan for integrated coastal management based on the Government's environmental, community and economic objectives for the island.
\end{abstract}

\section{Introduction}

Within England and Wales shoreline management is regulated under the flooding and coastal change policy by the Department for Environment, Food \& Rural Affairs (DEFRA) and the Environment Agency. The first Shoreline Management Plans (SMPs) were prepared by 2001 (SMP1) and are considered nonstatutory documents. The first revisions (SMP2) were published in 2010; and subsequently are expected to be reviewed under an Environment Agency project called Shoreline Management Plan Refresh through 2019-2020.

Jersey is a Crown Dependency. It is autonomous and self-governing, with its own independent legal, administrative and fiscal systems. In 2018 the Government of Jersey commenced a Shoreline Management Plan (SMP) project, which follows a modified version of the DEFRA (SMP) guidance drawing on examples from other island nations (e.g. Guernsey and the Isle of Man). The need for this work was identified through a number of coastal studies and strategies going back to the 1990's; however, the timing of this project is directly linked with the 2021 update of the Island Plan for Jersey which sets out the spatial planning policy for the Island, seeking to meet development needs whilst protecting the character, heritage and ecological assets of the Island, including the coastline. The Island Plan will provide the link from flood modelling and mapping to implementation of the shoreline management policies that emerge from the SMP - the SMP evidence base will inform the Island Plan review and zoning of land for development. Being an Island the SMP will take an island wide approach considering impact from 360 degrees. The policy options developed will be bespoke to reduce uncertainty in long-term planning and priorities the delivery of coastal infrastructure maintenance work. 
Jersey has been divided into six Coastal Management Areas (CMAs) and 36 Coastal Management Units (CMUs) for ease of planning assessment and to aid discussion with stakeholders. CMAs are defined as management areas with consistent themes that help to facilitate and rationalise policy identification and appraisal. The following information was used to define the CMA boundaries:

- Previously considered Island Plan management policies;

- Coastal processes, current coastal defences and standards of protection;

- Flood zones and mapping;

- Land use and ownership;

- Cultural and Environmental Designations; and

- Historical and current issues or concerns.

The CMUs have been subsequently developed based on similar proposed policy intents to help community stakeholders understand the management plan both in the immediate and longer tem. It is envisioned that these could alter following the public consultation.

The delivery of the SMP aims to provide a proactive, climate resilient and sustainable approach to coastal management for Jersey, which will reduce flood and erosion risks to the community, environment and economy over three management epochs: present day (2020-2040), medium term (2040-2070) and long term (2070-2120). As part of the Jersey SMP is the production of an inaugural set of Jersey flood maps, as supported by an erosion assessment, for tidal inundation, overtopping and inland flooding which have been created to assess island-wide flood risk both in present day and in 100 years.

\section{Method}

The Jersey SMP requires an assessment of tidal flood inundation from multiple sources and erosion impacts. These technical maps then help to determine the flood priority areas for Jersey's defences over the planning horizons for integrated coastal management. It is this baseline, for Jersey where it is primarily influenced by flood risk, that an island wide approach considering impact from 360 degrees is applied. Similar to the UK the environmental impacts, economics and stakeholder requirements are all assessed against the risks; but with the understanding that land loss in key areas is not acceptable.

\section{Modelling Method}

The coastal inundation assessment of Jersey includes;

- Still Water Flooding; Inclusive of the effects of climate change to 2120;

- Offshore/Nearshore Wave Propagation Analysis with Joint Probability Analysis;

- Calculation of Wave Overtopping Rates; Input to wave overtopping model, inclusive of varying locations and defence configurations;

- Wave Overtopping Model; Propagation of wave discharge over existing defences; and

- Coastal Erosion, Beach Morphological Analysis and Scour Analysis.

While the work of the SMP also produced an inland inundation assessment which included surface water modelling through an Island-wide pluvial inundation hydraulic model; the management of these flood risks have not been addressed in this work beyond the note that the delivery of defence shoreline management will need to address upper catchment and drainage flooding.

\section{Coastal Flooding}

A Still Water Level (SWL) analysis was undertaken and these calculated sea levels were applied to the topography of Jersey to indicate the areas located below extreme sea level during a particular event. Still water inundation was assessed to provide the worst case representation of flooding, meaning that no joint probability analysis with waves was applied. This analysis has been undertaken for present day and the future by considering climate change to include the assessment of sea-level rise, resulting in four epochs to be investigated. The epochs considered represented present, short, medium and longterm epochs i.e. 2020, 2040, 2070 and 2120. 


\section{Wave Overtopping Flooding}

Flooding from wave overtopping of structures was based on a two stage approach to defining the wave climate through offshore calibration and transformation of offshores to nearshore and to the coastline.

1. Offshore Derivation and Wave Transformation

An existing wave model (WSP, 2016) was calibrated by applying offshore wave data from the UK Met Office's Wave Watch III European Waters Wave Model along the seaward model boundary. The calibrated wave model was used to transform offshore swell waves and local wind waves to the $25 \mathrm{~m}$ depth contour around the island. From this contour, waves were further transformed inshore via local models covering the low-lying embayments on the West, South and East coasts. The same event retum periods were analysed as for the still water level analysis. Based on recent work by NOC (Prime, 2018) wave (and wind) conditions used for the analysis were not modified for climate change.

\section{Overtopping Discharge Rates}

Long term records of measured waves and water levels were analysed via application of techniques developed as part of the JOIN-SEA joint probability analysis (JPA) approach (HR Wallingford, 2000) in order to establish the degree of dependence between waves and sea levels. We subsequently applied the Environment Agency/DEFRA (2005) JPA approach (Environment Agency /DEFRA, 2005, Ref 7) to derive marginal wave and water level distributions based on the most appropriate correlation coefficient. Wave overtopping discharge rates were estimated for the determined JPA 100\%, 5\%, $1.33 \%$ and $0.5 \%$ AEP events. The discharge rates were calculated using methods described in the European Wave Overtopping Manual (EurOtop, 2016) for selected structure cross-sections in different locations around the island. Since overtopping is a primary concern for the present day and short term horizon, analysis was undertaken for 2020 and 2040 epochs only for cross-sections in priority locations (with a known history of significant overtopping) and other locations where overtopping has occurred in the past.

Typical water level profiles were generated based on the St Helier tide gauge records, to provide an estimate of the duration of a flood inundation event occurring at each of the agreed cross sections along the study frontage. The calculated overtopping rate was applied as a localised discharge-time boundary condition in a 2D TUFLOW flood inundation model. SLR was included in the analysis to represent any change in duration and overtopping discharge.

\section{Erosion Assessment}

A review of historic beach profiles has been undertaken to assess historic changes in beach level. The historic profiles range from 1992-1999 and 2003. In most years, quarterly surveys were completed on a total of 31 beaches (Figure 1). The traditional surveys have been supplemented by considering beach levels obtained from an island wide DTM in 2017 in order to obtain a more recent snapshot of beach 'health' i.e. if levels have dropped since the historic surveys.

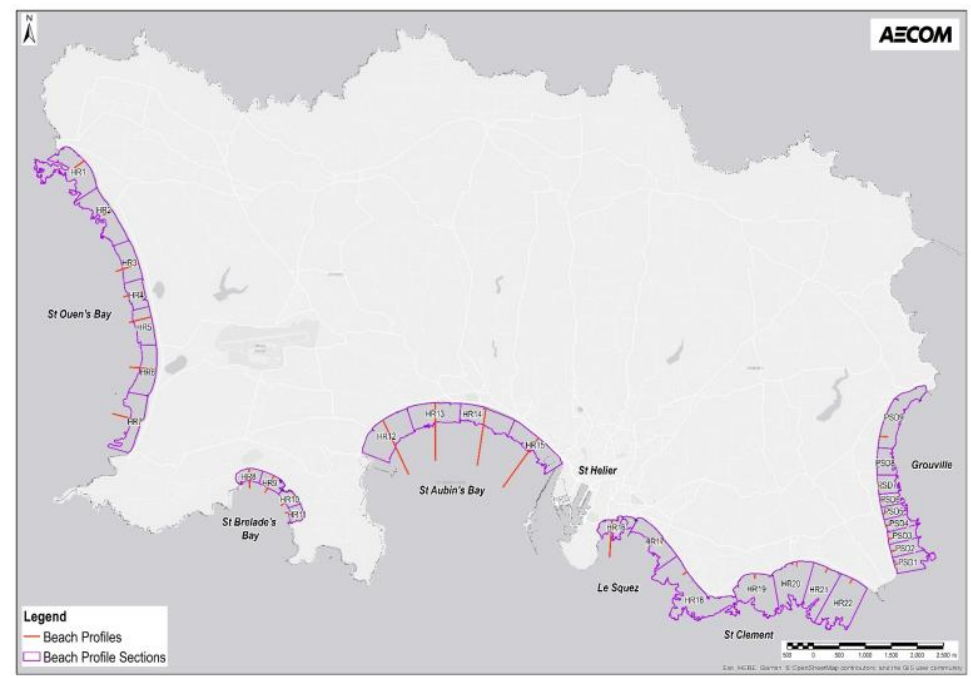

Figure 1: Beach Profile Areas of Extent around Jersey 
Whilst sometimes displaying switches between erosionary and accretionary behaviour between profile years, most beaches are stable for the period 1992-2003 with profiles typically varying in elevation by $10 \%$ or less. There is negligible evidence of changes in beach plan shape, which also suggests that beaches are relatively stable.

For the purposes of the SMP a historic erosion rate has been projected to other soft cliff areas, through adding a $0.3 \mathrm{~m} / \mathrm{yr}$ buffer to represent potential erosion over the next 100 years. This assumes historic environmental (marine, atmospheric, geomorphological and geological) conditions continue in the future as predicted. Whilst the 'extrapolation' method is limited in assessing future change, because of the lack of historic evidence of eroding beaches and the available data, it is considered that this is an appropriate methodology for the SMP to identify areas of coastline that are vulnerable and exasperated by sea level rise and inform planning policy development.

\section{Economics Method}

The economic appraisal supports the policy evaluation process in line with the HM Treasury Green Book. Although Jersey is outside of the United Kingdom and funding for coastal defences comes from the Government of Jersey, the economic appraisal methodology adopted is consistent with the Environment Agency's FCERM Appraisal Guidance (FCERM-AG, 2010) as it represents industry accepted best practice.

The economic viability of implementing the preferred SMP policy intent has been supported by a proportionate damage assessment and economic appraisal. The assessment has utilized the flood modelling of various return periods for each scenario over each epoch using the tidal flood inundation and wave overtopping maps, island property valuation data, and high level cost estimates for policy implementation options.

The first stage of the economic appraisal was to determine the potential flood damage with Present Management; dramatically differing from the DEFRA approach where the baseline flood damage is done against the No Active Intervention (NAI) scenario. The Present Management reflects where the existing defences would be maintained and repaired, with remedial and additional works carried out where necessary. However, adaptation to sea level rise or other climate change responses would not be addressed. Under this scenario the existing defences along the coastline will be maintained until the end of their residual life. Flood risk would increase significantly over time due to sea level rise, resulting in increased risk to properties behind the defences in the future. This scenario does not acknowledge the presence of de-facto defences. Developing this scenario is an essential part of the appraisal because it provides the baseline from which the preferred management options can be compared against to demonstrate the economic benefits of policies which result in an improved standard of protection or mitigate the effects of climate change. This is bespoke to Jersey and reflective of the Government of Jersey commitment that the current defences will always be maintained.

The second stage of the appraisal has been to determine the benefits of the preferred policies and establish the economic case for investment. The review has been undertaken Island-wide, as well as for each CMA and each CMU, as the management intent is set at CMU level. The CMUs have previously been defined as part of the policy development process, with consistent themes within each which helps to facilitate and rationalise policy identification and appraisal.

For the present day there are 277 residential properties at risk from a 1 in 200 year $(0.5 \%$ AEP) flood event. There are also 183 non-residential properties at risk of flooding from the same return period event. Due to sea level rise, in 100 years' time there are approximately 1500 residential properties and 1300 non-residential properties expected to be at risk from a 1 in 200 year ( $0.5 \%$ AEP) event.

The damage values used in the assessment are based on guidance created for England in the MultiColoured Manual (MCM). These are based on the direct damages avoided (reduced flooding to property, people, assets and infrastructure) and a number of indirect damages avoided (e.g. health and wellbeing impacts of flooding). In addition, the preferred policy option costs have been established. To reflect the difference between these typical damage values used in assessments in England and the typical value of land and property in Jersey, a $24 \%$ uplift factor has been applied to each category in both the damages assessment and the economic appraisal. This is based on the location adjustment construction costs for Jersey, published by the Building Cost Information Service (BCIS) (2015).

A further qualitative assessment has been undertaken for impacts which cannot be quantified, such as critical infrastructure, access and egress from the Island and potential reputational risks to the Jersey 
finance sector. This will provide Government of Jersey with a quantitative valuation of the net costs of delivering the SMP. Qualitative commentary will also be provided in the economic appraisal on business disruption and GVA impacts. Particular attention will be paid to the island's financial services and legal industry which, along with other sectors, including tourism and agriculture contribute to the island's economy.

\section{Stakeholder Engagement Method}

Communication and engagement to stakeholders has been, and continues to be, a central aspect of the SMP. The approach taken was developed around the publication of a Communications Plan that was built on; identifying stakeholders, presenting the type and frequency of consultation require and recording any consultation carried out.

The approach to consultation follows the Government of Jersey OASIS (Objectives, Audience Insight, Strategy, Implementation and Scoring) communications planning template. The stakeholder list was carefully considered covering a range of backgrounds, including; government, business, media, utilities, parish representatives, third sector, community and the general public .

A programme of events was established to reach out to interested parties, and this commenced in October 2018 through a formal introduction to the project to elected politicians and members of the Shoreline Climate Resilience Group (SCRG). The SCRG membership is composed of representatives from key Government of Jersey departments which spans the range of teams in making the development of the SMP cross-cutting between sectors.

\section{Results}

Priority area flood maps are presented in Figures 2-6 for coastal flood inundation and wave overtopping, respectively. A number of key observations were made from inspection of the maps to focus on economic, environmental and community benefits for the island. In summary, the maps show:

\section{Coastal Flooding}

In 2020, coastal flooding is very limited (Figure 2). The main area affected is in St Helier around the harbour. This is an active waterfront, utilised by leisure boating amenity users and the Maritime Museum is in the flood zone.

By 2120 several areas are affected and these are, principally, in the southeastern corner of the island. However, inundation is constrained by the coastal defences in some locations. For example, in Beaumont, near the Gunsite slipway, coastal inundation would occur without the existing defences and a flood board in place at the top of the slipway i.e. this area benefits from the defences. Similarly, large parts of Grouville would be inundated without the presence of the coastal defences, as well as St Catherine's Bay. 


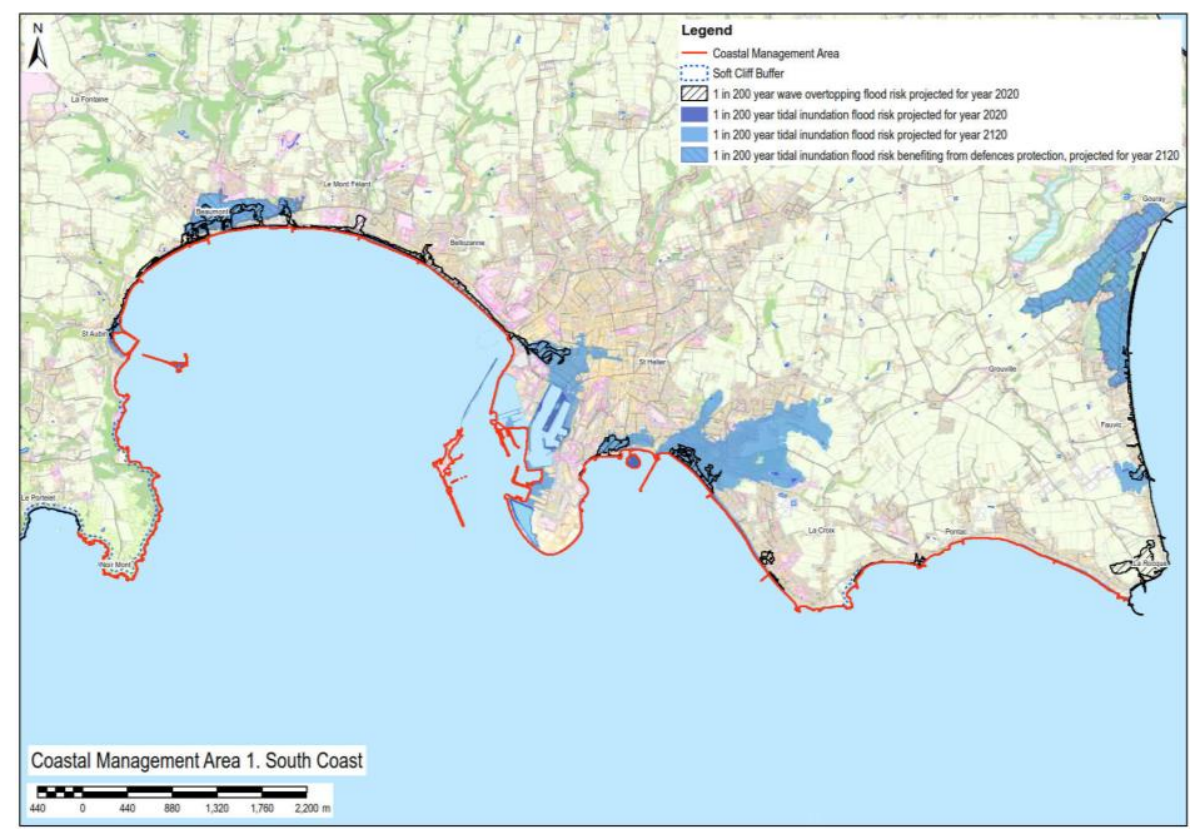

Figure 2: Coastal Flooding from 1 in 200yr return period projections along CMA1.

In other locations, inundation is projected to occur if the defences remain in their current form. The most significant areas are in and around St Helier. The flood zone extends northward from the harbour into the central business district of the town. Vulnerable assets include the Opera House, Liberation Bus Station, Jersey Museum and Art Gallery, the International finance centre, and access via the A1 would be disrupted. To the east, parts of Havre de Pas and Greve d'Azette would be under water, including the A4 and Green Road, and numerous residential, retail and hospitality businesses such as St Clements Golf and Sports Centre. The residential and leisure assets around St Aubin's Harbour are also predicted to be vulnerable in the future.

A closer view of CMU 1.2 (Figure 3) shows the presentation of the interaction of coastal flooding and predicted erosion and how both processes need to be considered in the development of the SMP policy.

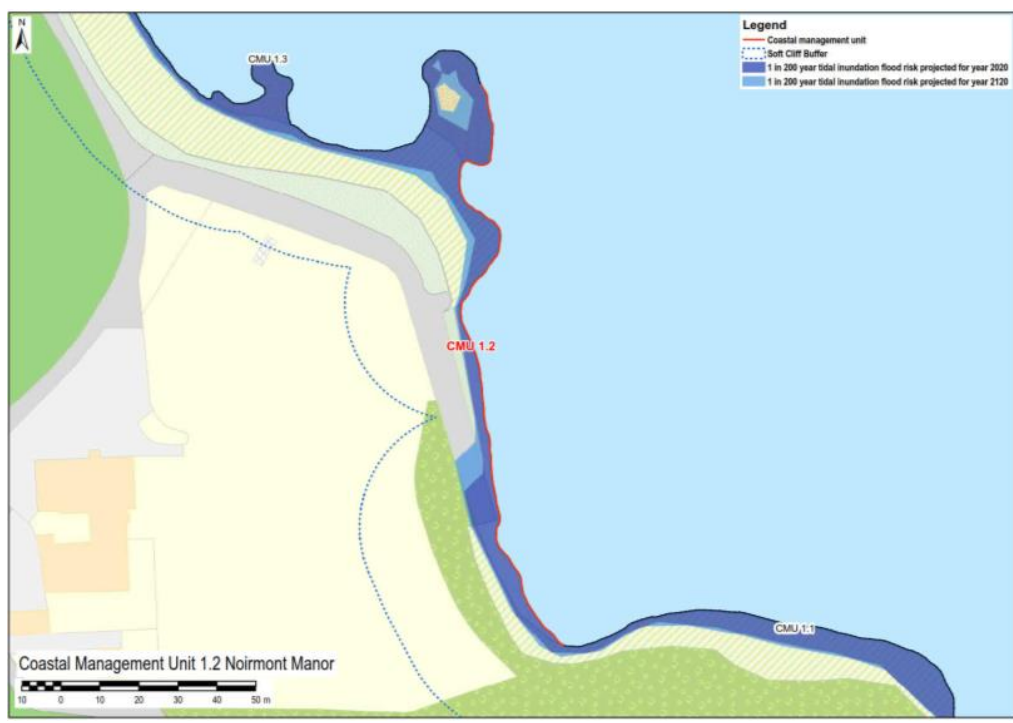

Figure 3: Coastal Flooding and Soft Cliff Buffer Zone at CMU 1.2 Noirmont Manor.

\section{Overtopping Flooding}

The hatched areas in Figure 4 shows the locations where overtopping discharge is predicted to extend in 2020 and 2040. The key message drawn from these figures is that several areas would overtop in the 
present day; this is not a surprise since the public experiences this, and historically, for more frequent return periods. The 2040 overtopping map reinforces the predictions for 2020 i.e. highlighting that the impacted areas are constant but increase in flood extent. The areas subject to overtopping are also, particularly for the south coast, coincident with areas that are predicted to experience coastal flooding in the future.

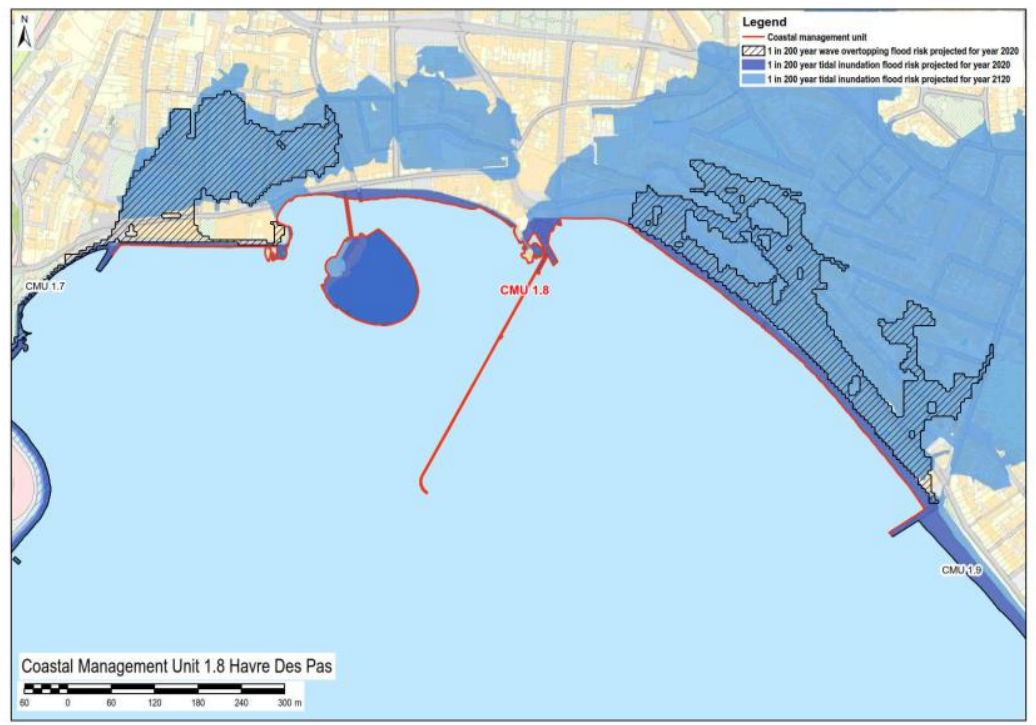

Figure 4: Coastal Overtopping 1 in 200yr return period projections for 2020 at CMU 1.8 Havre Des Pas.

\section{Discussion}

Currently, residents of Jersey are unable to access flood or erosion maps to understand the level of risk, and one of the key objectives of the SMP is to fill this gap complimented with the future plan for protection. The flood and erosion risk maps for the next 100 years, will be used by the Government of Jersey to deliver strategic development objectives of the Island Plan, understand the extent of damage from flood events, build into the planning process to guide inappropriate development from predicted flood risk areas and provide those with a vested interest (public or private) with definitive flooding data, which can be referred to in a consistent manner across the island's Government and industry.

Whilst the DEFRA SMP approach developed in England and Wales provides a useful baseline for coastal management strategies, different geographies, particularly small islands like Jersey, require a bespoke application. In Jersey the main driver is flooding and overtopping (particularly tipping points along key access routes); erosion is secondary as beaches are viewed as relatively stable and limited soft cliffs are present around the island.

While there are four coastal management policies for Jersey, similar to that in the United Kingdom, however their meaning and application are very different to reflect the priorities in Jersey. Specifically, differences can be noted where Jersey only promotes the application of an NAI policy to their natural coastlines that are currently undefended (both soft and hard) and where there is no future flood risk to infrastructure. The Government of Jersey manages their coastline with a fundamental baseline that the plan does not allow defended and/or developed land to be lost to the sea. For all policy assessment this leads to a scenario where the present management acts as the baseline; there is no 'do nothing'.

The Jersey SMP focuses on the narrative of the management plan and how defences will be implemented over time rather than at set points in time. This is an innovative step for Jersey, who to date has worked in real time maintenance approach and lacked formal integration with their own Island Plan. Where Jersey will potentially surpass the DEFRA approach is through their ability to capitalise on the timing and opportunity to rewrite planning policy and also to inform decision making on government plan priorities. Jersey are not doing the SMP to apply for external funding as that it not available, rather the SMP is being used to make tough choices about what can be done with the resources available in 
a sustainable way. The SMP policy starting point is to protect; as land is scarce and the primary constraint; this is a fundamental and important point of difference from DEFRA guidance.

The SMP policy assessment approach considered the relative merits and appropriateness of existing and future policy options using a consistent, and systematic scoring routine. The scoring of each policy option is based against the four core themes of defence, community, environment and economy; with each theme encompassing a number of sub-criteria with cumulative weightings. The policy option with the highest score was selected as the preferred policy option for public engagement. The proposed planning policies will be shared in the public consultation.

In the undertaking of this assessment it was recognised that there is no Hold the Line policy option; rather the focus is on Maintain or Managed Adaptation is primarily based around differing coastal defences; rather than allowing natural coastal processes take hold when land is limited and precious on an island. While the Maintain policy would be to 'keep good' what is currently there; Jersey has taken a proactive approach to Managed Adaptation to allow the implementation to be a blend of defences. This could include property based resilience combined with community awareness in pockets within the CMU's where overtopping is the dominant flood risk; to raised or extended sea defences where tidal inundation drives flood risk. It is recognised that in the longer term this changes what the coastline and beaches will look like and that innovative ways to compensate for lost coastal habitat will need to be considered; but this demonstrates that for Jersey coastal resilience is delivered through land protection.

This policy appraisal work is further supported by the economic assessments, where unlike the UK, in Jersey this assessment primarily supports the prioritisation of works rather than a business case. There are areas where the SMP recommends investment in a defence management scheme; but the benefit cost ration does not meet unity. For example, CMU 1.10 (Pontac) has a range of coastal defences but is still subject to overtopping flood risk at Le Hocq from a 1:1 Year flood event in the present day. Le Hocq is also predicted to be at risk of flooding from still water levels in the third epoch from a 1:200 year flood event, due to sea level rise. Between Green Island and Le Hocq, there is risk of erosion due to the soft geology (Figure 5). The policy options considered in CMU 1.10 are assessed against the policy objectives; leading to a preferred policy option of Adaptive Management in the first and second epochs and Maintain in the third epoch, up to 2120; protecting eight properties and an indicative BCR of 0.82 . Jersey's ability to protect this shoreline is supported by their approach to adaptive management through implementing, and taking economic benefit, from community awareness schemes during the first epoch to reduce and enable better preparation for the impacts of flooding on the community, and then engaging with the community to improve the defences to a 1:200 year standard of protection in the second epoch.

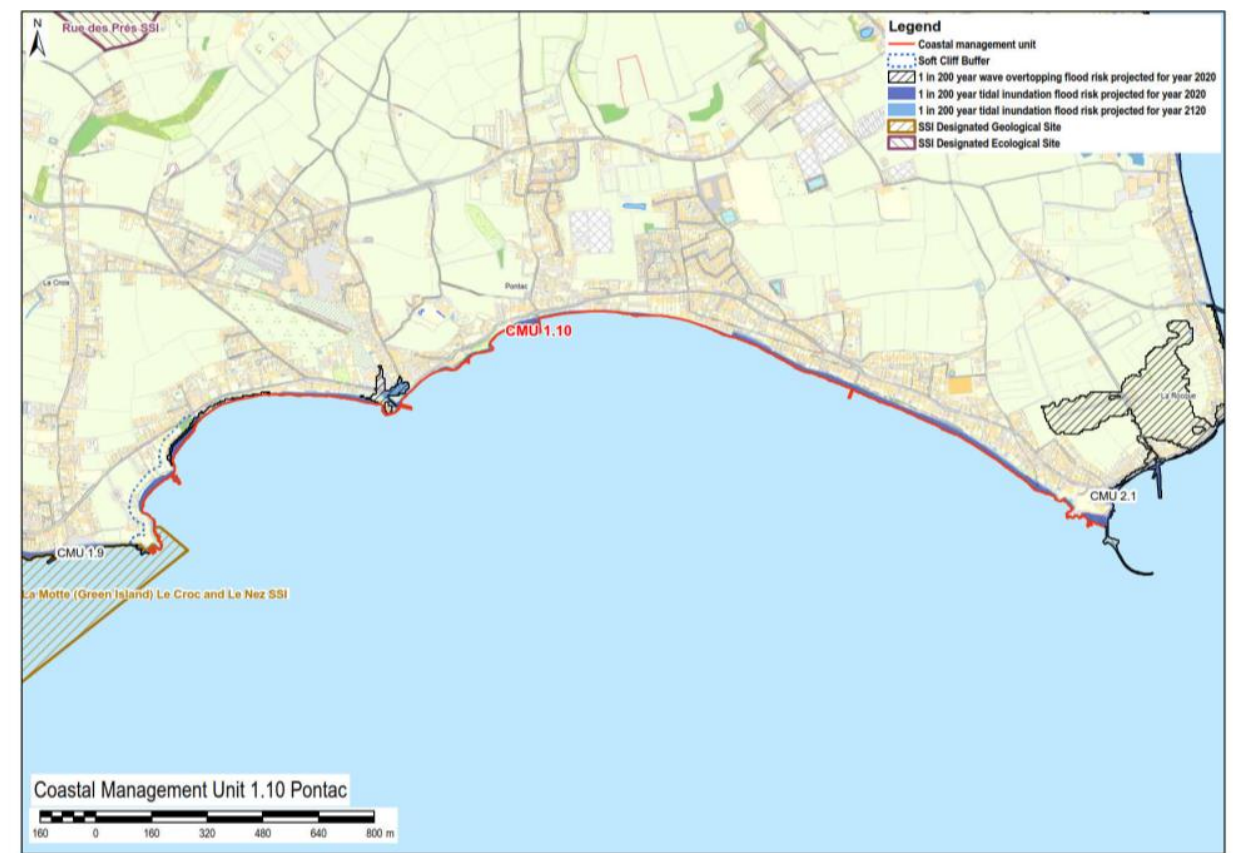

Figure 5: CMU 1.10 Pontac. 
While large parts of the island, particularly in the south and east are linked to development and infrastructure; the Jersey SMP policies strongly support natural coastal processes along areas like the majority of the north coast and in localised areas around the island primarily where stunning beaches are located and well-used for community recreation and tourism. Where examples of inappropriate development has taken place the SMP is taking firm decisions that no government investment will be put into defences and future planning policy will not allow new development. One particular example is CMU 4.5 (Egypt) which comprises the coastline from Fort Leicester to Bonne Nuit Harbour. The unit is undefended, though there is negligible flood risk. There is a risk of coastal erosion due to the soft geology, which is predicted to impact Cheval Roc Residential and Nursing Home, and potentially both Les Nouvelles Charrières and Les Charrières de Bonne Nuit Roads (Figure 6).

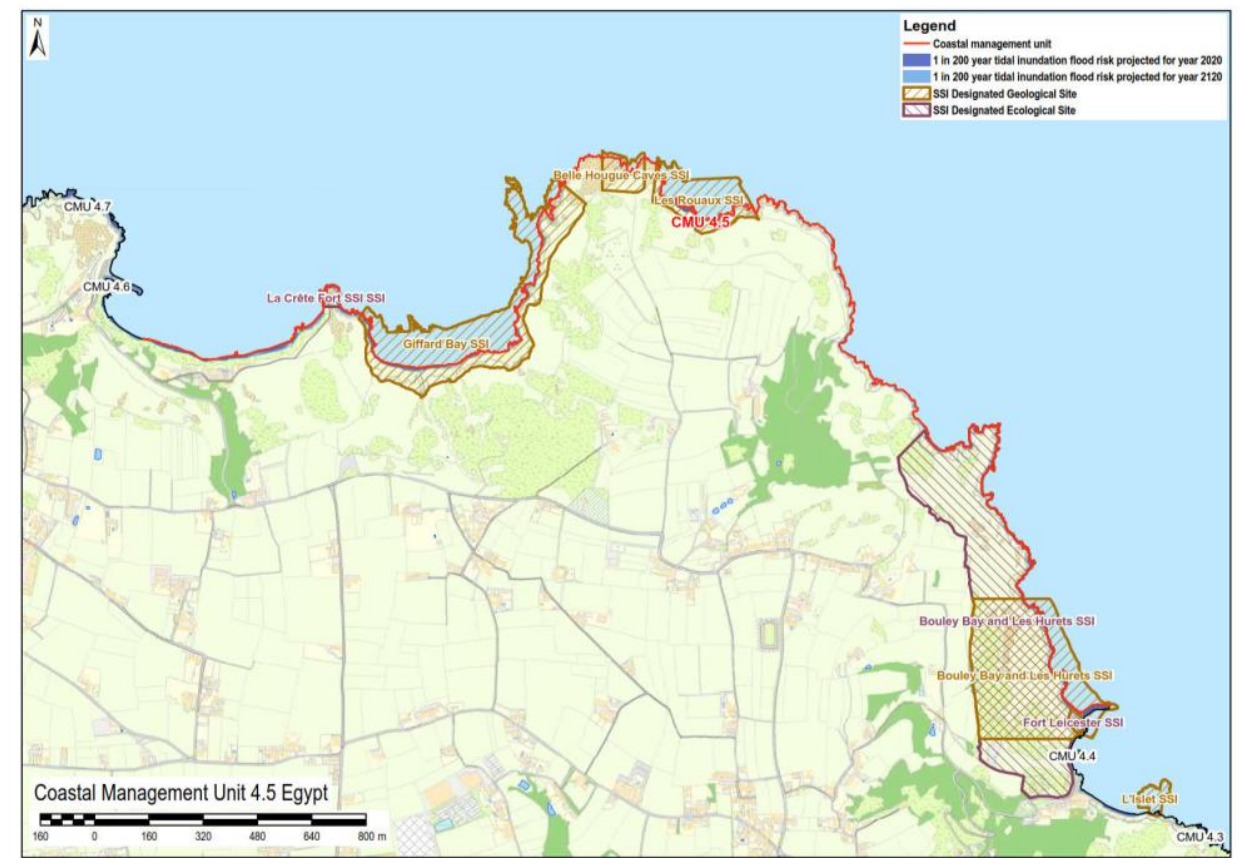

Figure 6: CMU 4.5 Egypt.

The policy options considered in CMU 4.5 are presented against the policy objectives and the preferred policy option for this unit is No Active Intervention for all three epochs. This will involve allowing natural processes to continue up to 2120 , and the implementation of any new defences will not be carried out by Government of Jersey. However, at the coastline directly in front of the Residential and Nursing home, the implementation and maintenance of privately funded assets is permitted, subject to Government planning policy and regulations. This is only justified in providing protection to existing assets, and should not be used to encourage new development in the area. The management intent will maintain the status of ecological processes and the lands cape value of the area, without introducing new infrastructure which could compromise the character of the coastline. This recognises the importance of the SSIs to the community, supporting the Island Vision objective to protect the land of SSls and the coastline.

\section{Conclusion}

The Jersey SMP arguably pushes the boundaries in traditional DEFRA style SMPs in terms of economics and prioritisation of works; alongside a completely different perspective around adaptive management and how this is implemented. For Jersey long term resilience against climate change is about island protection; recognising that this is deliverable through a reliance on coastal defences and proactive shoreline management planning policy. For this Island an island-wide approach must integrate with the Island Vision. This provides opportunity to explore advance the line options as space and local energy generation are of high priority.

With new flood risk information being made available to residents and visitors to Jersey, the need for clear communication with stakeholders on what the flood and planning maps mean will be pivotal to the 
successful delivery of the SMP. The stakeholder communication plan includes sufficient programme, utilising various approaches to get the message out to stakeholders, via a webpage https://www.gov.je/Environment/GenerateEnergy/Pages/index.aspx, social media, focused meetings, public events, and newsletters.

\section{References}

HR Wallingford (1991), Jersey Coastal Management Study. HR Wallingford Report EX2490, December 1991.

HR Wallingford (2009), The effects of climate change on Jersey's Coastal defence structures. Report EX5964, Release 6.0.

Prime (2018), Jersey sea level and coastal conditions climate review. National Oceanography Centre.

WSP (2006) Jersey Coastal Model. Version 2 (Public), Project no. 70011112. January 2016. 